\title{
3D Cocultures of Osteoblasts and Staphylococcus aureus on Biomimetic Bone Scaffolds as a Tool to Investigate the Host-Pathogen Interface in Osteomyelitis
}

\author{
Raffaella Parente ${ }^{1}\left(\mathbb{D}\right.$, Valentina Possetti ${ }^{1}\left(\mathbb{D}\right.$, Maria Lucia Schiavone ${ }^{1,2}$, Elisabetta Campodoni ${ }^{3}{ }^{(\mathbb{D}}$, \\ Ciro Menale ${ }^{2,4}{ }^{\oplus}$, Mattia Loppini ${ }^{1,5}$, Andrea Doni ${ }^{1}$, Barbara Bottazzi ${ }^{1}{ }^{1}$, Alberto Mantovani ${ }^{1,5,6}$, \\ Monica Sandri ${ }^{3}{ }^{\complement}$, Anna Tampieri ${ }^{3,7}$, Cristina Sobacchi ${ }^{1,2, *}$ and Antonio Inforzato ${ }^{1,5, *}$
}

1 IRCCS Humanitas Research Hospital, 20089 Rozzano, Italy; Raffaella.Parente@humanitasresearch.it (R.P.); valentina.possetti@humanitasresearch.it (V.P.); marialucia.schiavone@humanitasresearch.it (M.L.S.); mattia.loppini@hunimed.eu (M.L.); andrea.doni@humanitasresearch.it (A.D.); barbara.bottazzi@humanitasresearch.it (B.B.); alberto.mantovani@humanitasresearch.it (A.M.)

2 National Research Council-Institute for Genetic and Biomedical Research (CNR-IRGB), Milan Unit, 20089 Rozzano, Italy; ciro.menale@unina.it

3 National Research Council-Institute of Science and Technology for Ceramics (CNR-ISTEC), 48018 Faenza, Italy; elisabetta.campodoni@istec.cnr.it (E.C.); monica.sandri@istec.cnr.it (M.S.); anna.tampieri@istec.cnr.it (A.T.)

updates

Citation: Parente, R.; Possetti, V.; Schiavone, M.L.; Campodoni, E.; Menale, C.; Loppini, M.; Doni, A.; Bottazzi, B.; Mantovani, A.; Sandri, M.; et al. 3D Cocultures of Osteoblasts and Staphylococcus aureus on Biomimetic Bone Scaffolds as a Tool to Investigate the Host-Pathogen Interface in Osteomyelitis. Pathogens 2021, 10, 837. https://doi.org/ $10.3390 /$ pathogens 10070837

Academic Editors:

Pasquale Marrazzo, Monica Cricca, Natalie Fischer, Claudia Nastasi and Daniela Fusco

Received: 1 June 2021

Accepted: 29 June 2021

Published: 3 July 2021

Publisher's Note: MDPI stays neutral with regard to jurisdictional claims in published maps and institutional affiliations.

Copyright: (c) 2021 by the authors. Licensee MDPI, Basel, Switzerland. This article is an open access article distributed under the terms and conditions of the Creative Commons Attribution (CC BY) license (https:/ / creativecommons.org/licenses/by/ $4.0 /)$.
4 Department of Clinical Medicine and Surgery, University of Naples "Federico II", 80131 Naples, Italy

5 Department of Biomedical Sciences, Humanitas University, 20072 Pieve Emanuele, Italy

6 The William Harvey Research Institute, Queen Mary University of London, London E1 4NS, UK

7 National Research Council-Institute of Nanostructured Material (CNR-ISMN), 40129 Bologna, Italy

* Correspondence: cristina.sobacchi@humanitasresearch.it (C.S.); antonio.inforzato@humanitasresearch.it (A.I.); Tel.: +39-028-224-5153 (C.S.); +39-028-224-5132 (A.I.)

Abstract: Osteomyelitis (OM) is an infectious disease of the bone primarily caused by the opportunistic pathogen Staphylococcus aureus (SA). This Gram-positive bacterium has evolved a number of strategies to evade the immune response and subvert bone homeostasis, yet the underlying mechanisms remain poorly understood. OM has been modeled in vitro to challenge pathogenetic hypotheses in controlled conditions, thus providing guidance and support to animal experimentation. In this regard, traditional 2D models of OM inherently lack the spatial complexity of bone architecture. Three-dimensional models of the disease overcome this limitation; however, they poorly reproduce composition and texture of the natural bone. Here, we developed a new 3D model of OM based on cocultures of SA and murine osteoblastic MC3T3-E1 cells on magnesium-doped hydroxyapatite/collagen I (MgHA/Col) scaffolds that closely recapitulate the bone extracellular matrix. In this model, matrix-dependent effects were observed in proliferation, gene transcription, protein expression, and cell-matrix interactions both of the osteoblastic cell line and of bacterium. Additionally, these had distinct metabolic and gene expression profiles, compared to conventional 2D settings, when grown on $\mathrm{MgHA} / \mathrm{Col}$ scaffolds in separate monocultures. Our study points to $\mathrm{MgHA} / \mathrm{Col}$ scaffolds as biocompatible and bioactive matrices and provides a novel and close-to-physiology tool to address the pathogenetic mechanisms of $\mathrm{OM}$ at the host-pathogen interface.

Keywords: Staphylococcus aureus; osteomyelitis; osteoblast-like cells; host-pathogen interface; 3D models; biomimetic bone scaffolds

\section{Introduction}

Osteomyelitis (OM) is an inflammatory disease of the bone caused by a wide range of opportunistic pathogens, including the Gram-positive bacteria Staphylococcus aureus (SA), S. epidermidis, Streptococcus pyogenes, and Pseudomonas aeruginosa and the Gram-negative Escherichia coli [1]. In children OM primarily results from the hematogenous spread of the pathogen from distant sites of infection [2], whereby in adults most cases of OM originate 
from bone contamination during invasive surgical procedures, particularly, fracture fixation and arthroplasty [3]. Regardless of how the infectious agent colonizes the bone, a series of pathogenetic events follows that eventually leads to dramatic alterations and a loss of diverse bone compartments, including trabecular and cortical bone, marrow, periosteum, and the surrounding soft tissue [4]. Aggressive antimicrobial treatments are the standard of care for $\mathrm{OM}$ [5], however antibiotic resistant strains are emerging that undermine efficacy of the currently available therapeutic options [6].

The ubiquitous commensal SA is responsible for up to $75 \%$ of OM cases [7], likely due to a remarkable tropism for bone tissue and the exploitation of several strategies of adaptation and resistance [8-11]. The bone-invasive properties of SA likely arise from a variety of microbial surface components recognizing adhesive matrix molecules (MSCRAMMs) that mediate the recognition of and adherence to bone extracellular matrix (BEM) components, like type I collagen, bone sialoprotein, osteopontin, fibronectin, and laminin [12]. Following adherence to the BEM, SA can target, for infection, a number of resident cell types, including bone forming (osteoblasts, OBs) and resorbing (osteoclasts, OCs) cells, where OB-dependent responses are believed to play a major role in OM pathogenesis [13]. Indeed, recognition of pathogen-associated molecular patterns (PAMPs) by OB-borne and OB-secreted pattern recognition molecules (PRMs) prompts synthesis and release of chemokines, cytokines, and growth factors (e.g., TNF- $\alpha$ and TGF- $\beta$ ) [14] that, in turn, promote recruitment and activation of immune cells (particularly, macrophages and neutrophils) $[15,16]$. Among the range of molecules expressed by OB lineage cells besides immune ones, the soluble PRM pentraxin 3 (PTX3) has been recently proposed as a specific and independent diagnostic and prognostic biomarker in opportunistic infections [17], including those sustained by SA $[18,19]$.

Furthermore, SA decreases both the activity and viability of OBs, via apoptosisdependent $[20,21]$ and apoptosis-independent [22,23] pathways, and alters redox homeostasis in these cells [24]. In addition, following an infection with SA, OBs produce more receptor activator of NF-kB ligand (RANKL) and less osteoprotegerin (OPG), which, in turn, promotes osteoclastogenesis and bone resorption $[25,26]$. These processes collectively contribute to perturbation and even loss of bone homeostasis [27], and highlight the key roles played by OBs at the host-pathogen interface in OM pathogenesis [13]. It is therefore conceivable that research into the crosstalk between OBs and SA will deliver novel information on the molecular mechanisms of OM. In this regard, animal modeling of the disease are invaluable as they integrate the structural and functional complexity of the natural bone, nonetheless addressing the OB-SA interface in vivo might be problematic due to the confounding and redundancy effects contributed by other cells of the bone [28]. On the other hand, conventional bidimensional (2D) in vitro models, based on either primary or immortalized cells (such as the human MG63 and murine MC3T3-E1 cell lines) allow direct investigation of the host-pathogen crosstalk (including formation of biofilms [3] and adaptation to slow-growing small colony variants, SCVs $[29,30])$ in a controlled setting. However, they are far from reproducing the physical and chemical cues of the skeletal tissue, with major regard to the organization of OBs in the bone matrix [3,31,32]. More recently, three-dimensional (3D) models of OM have been proposed that recapitulate some aspects of the bone tissue architecture and cellular complexity. A common limitation of the currently available 3D models of OM is poor reproduction, in the applied in vitro settings, of the natural BEM, which is an essential player in SA adhesion, biofilm formation, and infection of bone cells [12].

To overcome this issue, here we exploited biomimetic hybrid composite scaffolds manufactured with a biomineralization process that involves direct nucleation of $\mathrm{Mg}$-doped hydroxyapatite/collagen I (MgHA/Col) [21]. These scaffolds incorporate the major organic (collagen I) and mineral (hydroxyapatite) components of the authentic bone matrix in a porous structure, which likely provides not only structural support but also biomechanical and chemical clues to the cultured cells, different to other synthetic matrices that lack either hydroxyapatite or collagen or both $[6,33]$. Taking advantage of these unique features of the 
MgHA/Col scaffolds, here we implemented a novel 3D model of OM based on murine osteoblastic MC3T3-E1 cells infected with a clinical isolate of SA. Functional adaptation of cells to the applied 3D environment was investigated, which highlighted major differences to conventional 2D cultures on untreated plastic surfaces. Additionally, early phases of the SA infection were studied that suggest matrix-dependent effects on the expression of primary mediators of the $\mathrm{OB}$ function. In addition, we found profound differences in the expression of SA virulence genes known to participate in adhesion to the bone matrix, recognition of OBs, and biofilm formation. Therefore, we established a novel strategy to model OM in vitro that is likely to provide pathologically relevant insights into molecular and cellular processes of OM at the host-pathogen interface.

\section{Results}

\subsection{Adaptation of MC3T3 Cells to 3D Cultures on $\mathrm{MgHA} / \mathrm{Col}$ Scaffolds}

To establish an MgHA/Col-based 3D model of bone infection, the number and metabolic activity of MC3T3-E1 cells were assessed when these were cultured on biomimetic scaffolds in the absence of SA. A total of $1 \times 10^{6}$ MC3T3-E1 cells / scaffold were seeded and genomic DNA (as an index of cell proliferation) was quantitated at 3, 6, and 9 days from seeding using the PicoGreen assay. Cells proliferated from day 3 to 6 and no further expansion was observed after day 6 (up to day 9), when a stationary growth phase was achieved (Figure 1A). As opposed to this, the rate of reduction of resazurin to resorufin (that generates a fluorescence signal in the applied Alamar Blue assay and is an index of metabolic activity) decreased from day 3 to 6 and remained stable afterwards (up to day 9) (Figure 1B). These findings indicate that the MC3T3-E1 cell line expands on (Figure 1A) and metabolically adapts to (Figure 1B) the MgHA/Col scaffolds, which therefore proved to be biocompatible in the applied experimental conditions. Prompted by these observations, we analyzed the expression of major osteogenic, inflammatory and oxidative stress responserelated genes in MC3T3-E1 cells cultured in stationary conditions on MgHA/Col scaffolds (i.e., at 6 days from seeding), and compared it with that of the same cells in conventional subconfluent 2D cultures (with comparable cell counts). We found significantly higher mRNA levels of osteoprotegerin $(O p g$, which together with Rankl is a key mediator of the OB-OC crosstalk and bone homeostasis [34]), bone morphogenetic protein 2 (Bmp2, which plays an important role in inducing the osteogenic differentiation of mesenchymal stem cells [35]), and secreted phosphoprotein 1 (Spp1, coding for osteopontin, a marker of late osteogenic differentiation involved also in infection [26,36]), in 3D-versus 2D-cultured cells. This result was in agreement with the previously reported osteoinductive properties of MgHA/Col scaffolds [37-39]. Additionally, we observed lower expression both of the alkaline phosphatase (Alp) and collagen type $1 \alpha 1$ chain (Col1a1) genes when cells were adapted to the $3 \mathrm{D}$ setting, as compared to cultures on plastic surfaces (Figure 1C). These genes are markers of the preosteoblast and mature osteoblast phase. In particular, Alp is known to be reduced in mature as compared to immature osteoblasts [38], it is plausible that the MgHA/Col scaffolds favor transition of the MC3T3-E1 cells towards a more advanced stage of differentiation, possibly via BEM-cell interactions. This might also explain why Col1a1 was downregulated when cells were grown in the collagen-rich microenvironment of the scaffolds (Figure 1C). In line with this interpretation, expression of zonula occludens-1 (Zo-1, involved in cell-cell interaction) was reduced in our 3D setting, suggesting that the MC3T3-E1 cells are engaged in BEM-cell rather than cell-cell contacts when they are seeded on MgHA/Col matrices (Figure 1C). As opposed to this, no differences were found between 3D and 2D cultures in the expression of selected inflammatory markers, including tumor necrosis factor- $\alpha$ (Tnf- $\alpha)$, pentraxin 3 (Ptx3), and transforming growth factor- $\beta$ (Tgf- $\beta$ ). In addition, we measured the expression levels of genes acting in a master regulator pathway of the redox status of the cells, modulated also by SA infection of bone cells, i.e., the Keap1-Nrf2 pathway [40]. In our experimental conditions, the nuclear factor erythroid 2-related factor 2 (Nrf2) and heme oxygenase 1 (Ho-1) gene expression level was unchanged in the two culture models (Figure 1D). Overall, these data indicate 
that the MgHA/Col matrices not only are compatible with 3D culturing of MC3T3-E1 cells, but also provide physical and chemical cues that reproduce some aspects of the BEM-cell interface in the natural bone.

A

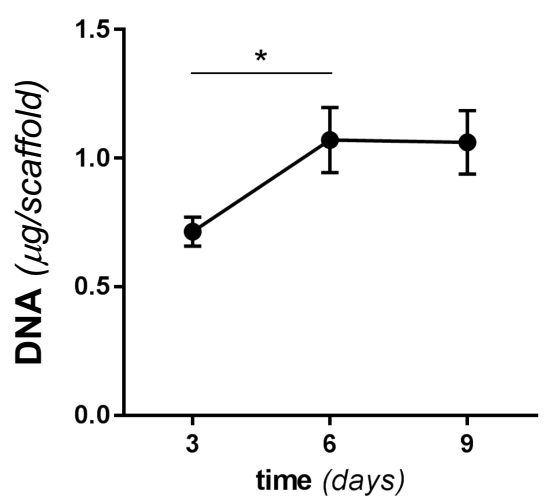

C

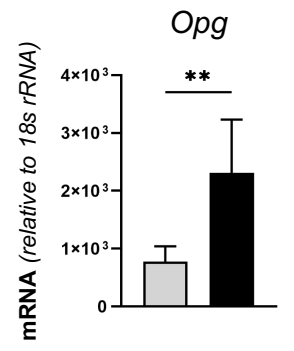

D

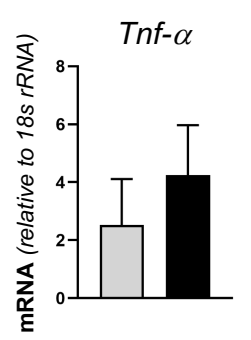

\section{Bmp2}

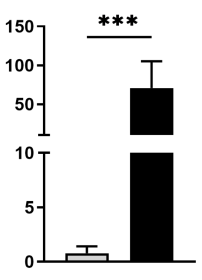

B

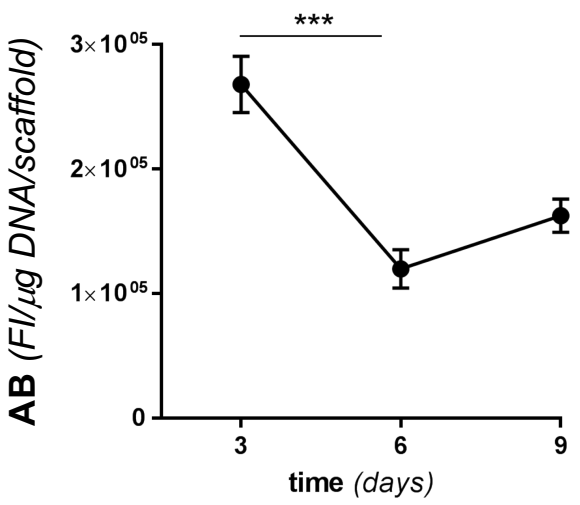

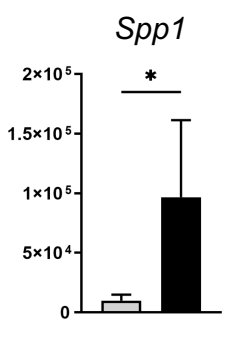
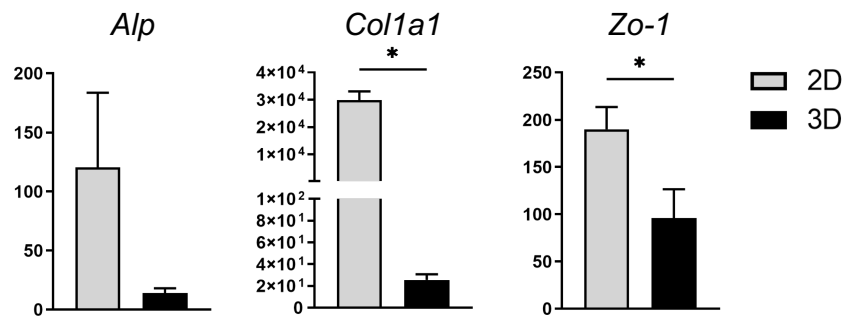

Figure 1. Proliferation, metabolic activity, and gene expression of MC3T3-E1 cell cultures on MgHA/Col 3D scaffolds. MC3T3-E1 cells were seeded on MgHA/Col 3D scaffolds at a concentration of $1 \times 10^{6}$ cells/scaffold and cultured for 9 days. (A) Cells were lysed and genomic DNA was quantitated using the PicoGreen assay at the indicated time points. Results are expressed as micrograms of DNA/scaffold. (B) The metabolic activity of viable cells was measured at 3,6, and 9 days from seeding using the Alamar Blue $(\mathbf{A}, \mathbf{B})$ assay. Results are expressed as fluorescence intensity (FI in arbitrary units)/ $\mu$ g of DNA/scaffold. Data in A and B are from 2 independent experiments performed in duplicate, $n=4$, mean \pm SEM. (C,D) Total RNA was extracted from MC3T3-E1 cells at day 6 from seeding (i.e., in stationary growth phase) and transcription (mRNA) of the indicated osteogenic (osteoprotegerin, Opg; bone morphogenetic protein 2, Bmp2; secreted phosphoprotein 1, Spp1; alkaline phosphatase, Alp; collagen type $1 \alpha 1$ chain, Col1a1) and adhesion (zonula occludens-1, Zo-1) (C) and inflammatory (tumor necrosis factor- $\alpha$, Tnf- $\alpha$; pentraxin 3 , Ptx 3 ; transforming growth factor- $\beta$, Tgf- $\beta$ ) and oxidative stress response (nuclear factor erythroid 2-related factor 2, Nrf2; heme oxygenase 1, Ho-1) (D) genes (mRNA levels) was determined by qRT-PCR. Results are expressed as normalized values based on 18S rRNA (3 independent experiments performed in duplicate, $n=6$, mean \pm SEM). In panels A to $C,{ }^{* * *} p<0.001,{ }^{* *} p<0.01$, and ${ }^{*} p<0.05$, Mann-Whitney test.

\subsection{SA Growth on $\mathrm{MgHA} / \mathrm{Col}$ Scaffolds}

We next investigated the adaptation of SA to the MgHA/Col matrices by assessing bacterial growth and scaffold colonization for 3 days from inoculum (a time window that spans the early phases of OM pathogenesis in vivo, when bacteria adhere to the natural bone [41]). To this end, $160 \times 10^{6}$ bacteria were seeded on empty scaffolds, and 
SA colonization of the bone-like matrix in the absence of cells was assessed by means of fluorescence microscopy and colony forming unit (CFU) counting. Widespread diffusion of bacteria along the scaffold's collagen fibers was apparent in immunofluorescence images taken $24 \mathrm{~h}$ postinfection (Figure 2A) and at later time points (data not shown). The number of SA CFUs retrieved from the MgHA/Col scaffolds was stable within 2 days from inoculum, indicating that the biomimetic matrix did not affect SA viability in this timeframe (Figure 2B). However, at day 3 the CFU count decreased, possibly due to partial biodegradation of and magnesium release by the MgHA/Col scaffolds (Figure 2B) [33].

A

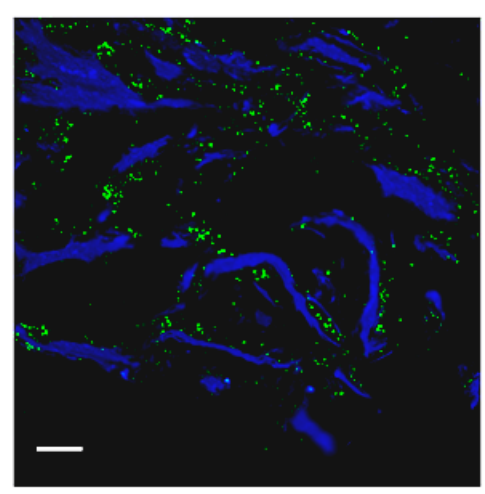

B

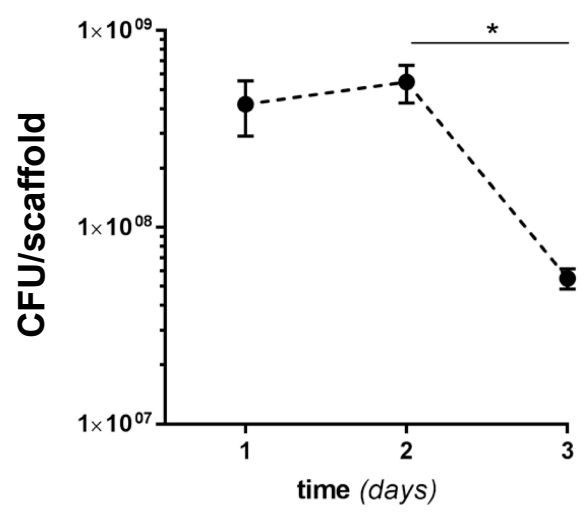

Figure 2. SA colonization of MgHA/Col scaffolds. MgHA/Col empty scaffolds were inoculated with $1.6 \times 10^{8}$ bacteria/scaffold, and SA colonization was assessed using fluorescence microscopy and CFU counting. (A) Following fixation and sectioning, SA cells on scaffolds were revealed using a FITC-conjugated anti-Staphylococcus aureus antibody (green) and collagen was recorded as blue autofluorescence. An image of SA-inoculated scaffolds harvested at $24 \mathrm{~h}$ from inoculum is shown that is representative of at least 3 independent experiments (scale bar: $64 \mu \mathrm{m}$ ). (B) CFUs were measured at 1, 2, and 3 days from inoculum. Results are expressed as CFU/scaffold ( 3 independent experiments performed in duplicate or triplicate, $n=6-8$, mean \pm SEM). ${ }^{*} p<0.05$, one-way ANOVA test with Dunn's multiple comparisons test.

\subsection{The 2D and 3D Cocultures of MC3T3-E1 Cells and SA}

We then infected MC3T3 cells with SA in 2D and 3D culture conditions and investigated both osteoblast's responses to the presence of SA and bacterial survival in the presence of MC3T3-E1 cells. Briefly, MC3T3-E1 cells were cultured for $24 \mathrm{~h}$ in 48 well plates (2D) or 6 days on MgHA/Col scaffolds (3D, to achieve a stationary growth phase; see Figure 1A), then challenged with SA at a multiplicity of infection (MOI) of 160:1. In the 2D setting, SA significantly reduced proliferation of the osteoblastic cells (Figure 3A) and increased their metabolic activity (Figure 3B) at 24, 48, and $72 \mathrm{~h}$ from infection. Additionally, the number of viable bacteria did not change in this time window in the $2 \mathrm{D}$ experiments (Figure 3C). As opposed to this, in the 3D model SA caused a reduction in MC3T3-E1 proliferation at $48 \mathrm{~h}$ from infection only, while $24 \mathrm{~h}$ later (i.e., $72 \mathrm{~h}$ from infection) the osteoblastic cells recovered (Figure 3D), likely due to poor SA adhesion and growth in these conditions (see below). Furthermore, the metabolic activity of the MC3T3-E1 cells was not affected by SA (Figure 3E). In addition, in this setting, the CFU count was unchanged throughout the coculture (Figure $3 \mathrm{~F}$ ) and less bacteria adhered to the MgHA/Col scaffolds in the presence of the MC3T3-E1 cells (see the $24 \mathrm{~h}$ time point in Figures 3F and 2B for a comparison), suggesting that preincubation of the scaffolds with these cells might impair adhesion of SA to the 3D matrix. Moreover, our findings point to this osteoblastic cell line manifesting different behaviors in terms of survival and metabolic activity in 2D and 3D settings both in the presence and in absence of SA, further highlighting the biological relevance of the BEM-cell interface, which is missing in the $2 \mathrm{D}$ cocultures. 

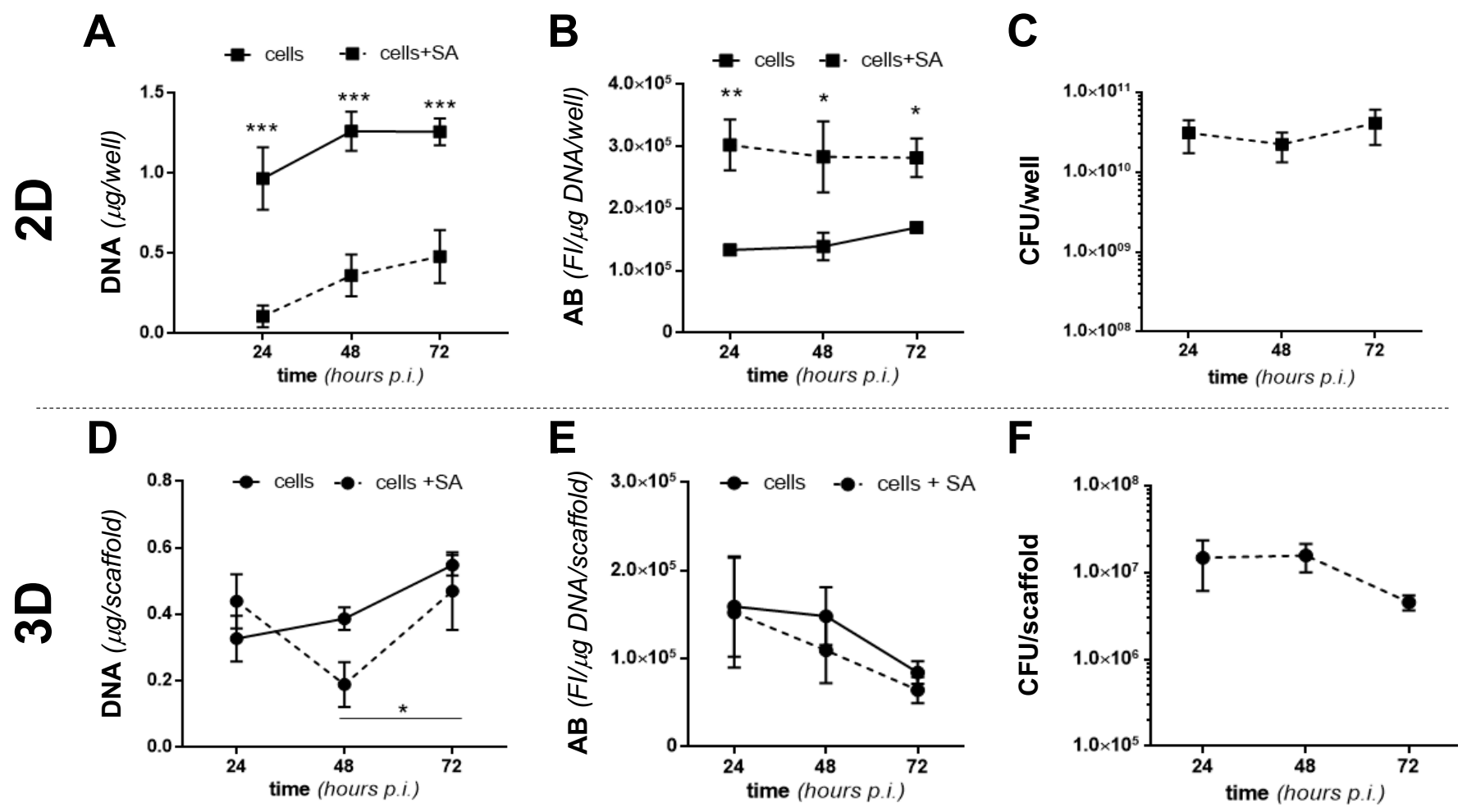

Figure 3. Proliferation and metabolic activity of MC3T3-E1 and SA in 2D and 3D cocultures. MC3T3-E1 cells were seeded in 48 well plates (2D) or on MgHA/Col 3D scaffolds (3D) and cultured for 1 or 6 days, respectively, to achieve comparable cell counts $\left(3 \times 10^{5}\right.$ cells/well or scaffold). Either live or inactivated (fixed) SA was then inoculated (MOI of 160:1) and cocultured with MC3T3-E1 cells for $72 \mathrm{~h}$. (A,D) DNA from MC3T3-E1 cells challenged with live SA was quantitated using the PicoGreen assay at the indicated time points (cell proliferation). Results are expressed as micrograms of DNA/well or scaffold in the absence (solid line) or presence (dotted line) of SA in the 2D (A) and 3D (D) settings. (B,E) The metabolic activity of MC3T3-E1 cells challenged with inactivated SA was measured at the indicated time points using the AB assay. Results are expressed as fluorescence intensity (FI in arbitrary units)/ $\mu \mathrm{g}$ of DNA/well or scaffold in the absence (full line) or presence (dotted line) of SA in 2D (B) and 3D (E) experiments. (C,F) CFU counts from live SA-MC3T3-E1 cocultures at 24, 48 , and $72 \mathrm{~h}$ from infection in 2D (C) or 3D (F) settings. In all panels, results are from 2 independent experiments performed in duplicate, triplicate, or quadruplicate, $n=4-8$, mean \pm SEM. ${ }^{* *} p<0.001,{ }^{* *} p<0.01$, and ${ }^{*} p<0.05$, two-way ANOVA with Sidak's multiple comparisons tests.

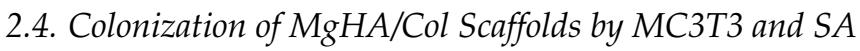

To assess colonization of the MgHA/Col scaffolds by MC3T3-E1 cells and SA, we analyzed cell-seeded matrices before infection and at different time points from SA inoculation, using fluorescence microscopy and scanning electron microscopy (SEM). Immunofluorescence analysis of scaffolds' sections showed that MC3T3-E1 cells adhered to the MgHA/Col meshwork and localized on the collagen fibers (Figure 4A). Additionally, upon infection, bacteria spread throughout the scaffold, localizing both on the collagen matrix and near MC3T3-E1 cells, and formed colonies (Figure 4B-D).

SEM analysis of empty scaffolds clearly showed the porous structure of these matrices and the spatial organization of the collagen fibers (Figure 5). In this peculiar microenvironment, SA localized on the matrix, maintaining its typical morphology while forming colonies (Figure 5B,C). MC3T3-E1 cells arranged along the collagen fibers (Figure 5D). After infection, close contacts between MC3T3-E1 cells, SA, and the matrix were observed, which were retained throughout the coculture (Figure 5E,F). 


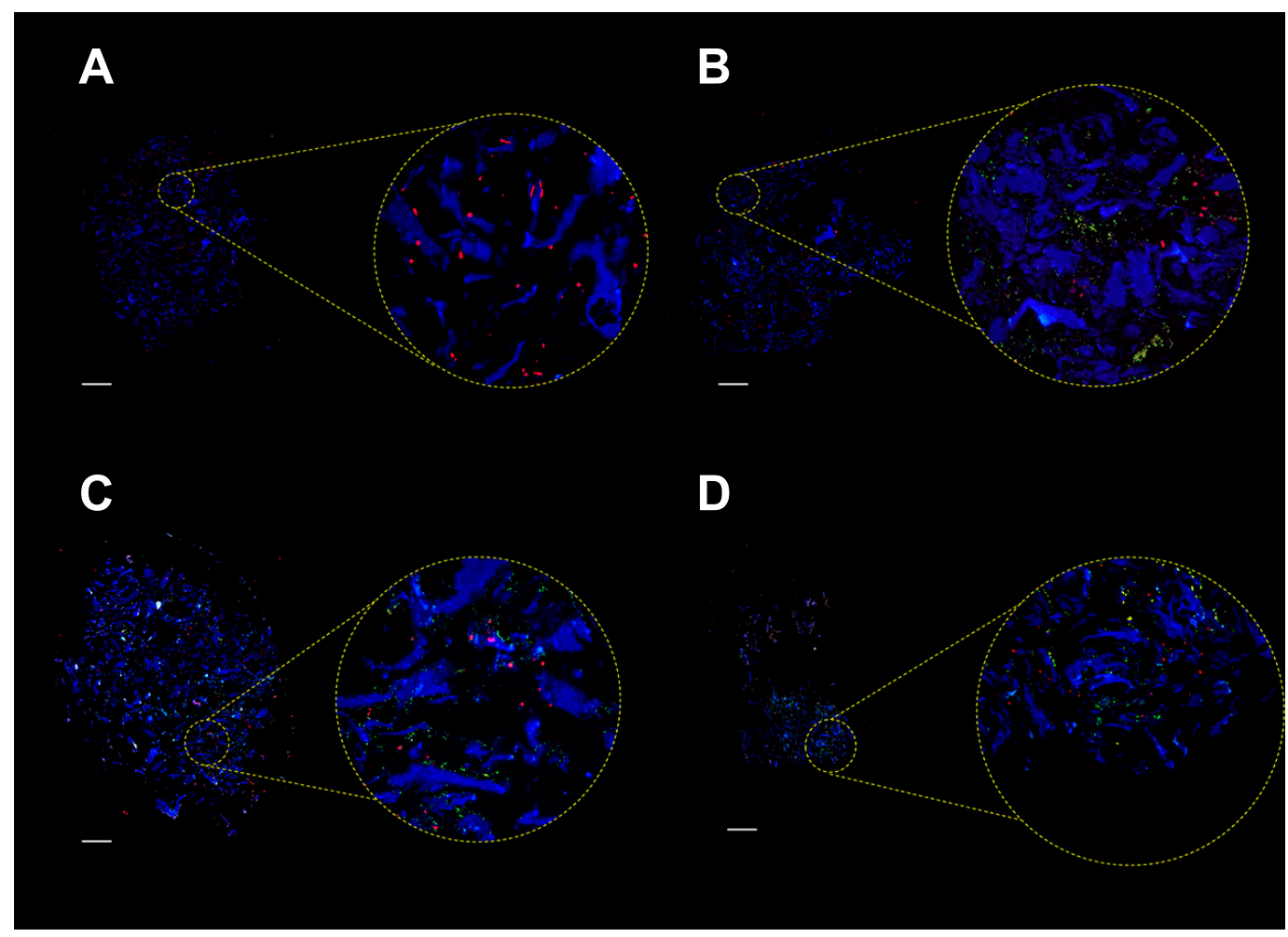

Figure 4. Immunofluorescence analysis of MgHA/Col scaffolds seeded with MC3T3-E1 cells and SA bacteria. MC3T3-E1 cells were seeded on MgHA/Col 3D scaffolds and cultured for 6 days. Live SA was then inoculated (MOI of 160:1), and cocultured with MC3T3-E1 cells for $72 \mathrm{~h}$. Fluorescence microscopy images (representative of 3 independent experiments) are shown that were obtained from scaffolds seeded with MC3T3-E1 cells only (A) or with MC3T3 and SA after 24 (B), 48 (C), and 72 (D) hours of coculture. Bacteria were revealed using a FITC-conjugated anti-Staphylococcus aureus antibody (green), nuclei were stained with propidium iodide (red), and collagen autofluorescence was collected as a blue signal. Yellow spots in the images are due to colocalization of green and red fluorescence, and likely indicate SA cells. Scale bar represents $400 \mu \mathrm{m}$.

\subsection{Gene Expression and Protein Levels of SA-Infected MC3T3-E1 Cells}

To characterize further our in vitro model of SA infection of the bone, we assessed the expression of selected genes in SA-infected MC3T3-E1 cells cultured in 3D conditions at early times (from 3 to $18 \mathrm{~h}$ ) from infection. In particular, we focused on a set of genes that are paradigms of the cell inflammatory and oxidative stress response. Amongst these, mRNA of the inflammatory cytokine TNF- $\alpha$ increased over time with a peak at $18 \mathrm{~h}$ from infection. Accordingly, transcription of Ptx3, which is involved in bone remodeling [18,42] and is known to be induced by TNF- $\alpha$ [43] was significantly increased $18 \mathrm{~h}$ postinfection. Interestingly, Tgf- $\beta$ mRNA had an opposite trend with a clear reduction at $18 \mathrm{~h}$ (Figure 6A). A similar (to Tgf- $\beta$ ) expression kinetic was observed for Nrf2 and its downstream effector Ho-1: the former had significantly decreased transcription at $18 \mathrm{~h}$ from infection, and the latter was less expressed at $6 \mathrm{~h}$ already and had consistently reduced mRNA levels up to $18 \mathrm{~h}$ from infection. Comparable results were obtained in the 2D setting (see Figure S2 in Supplementary Materials), with the noticeable exception of Ptx3, whose transcription was reduced in these conditions. It is worth noting here that SA-infected MC3T3-E1 cells were less viable in the 2D than in the 3D setting at $24 \mathrm{~h}$ from infection (Figure 3A), which made it problematic to perform comparative gene expression analysis at longer times. Prompted by our observation that the MgHA/Col scaffolds affected expression of key osteogenesisrelated genes in MC3T3-E1 cells cultured in the absence of SA (see Figure 1C), we extended our investigations to 3D cocultures of MC3T3-E1 and SA. Despite these matrix-dependent effects, the mRNA levels of $O p g, B m p 2$, and Spp1 did not change significantly during the infection (Figure 6B), consistent with the reported antiosteogenic effects of inflammation 
and infection [44,45]. Additionally, a decremental trend was observed in the transcription of Alp (Figure 6B).
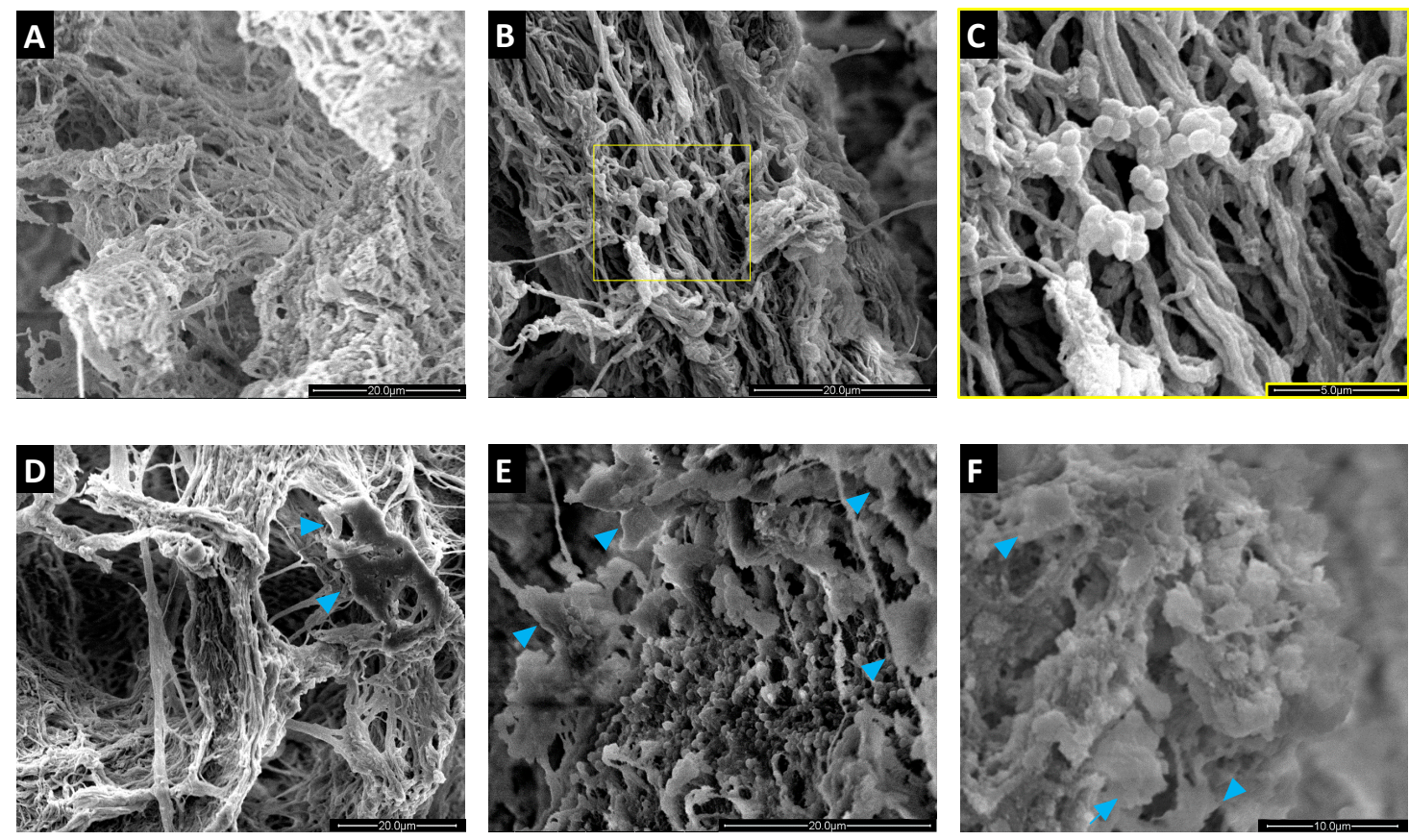

Figure 5. Scanning electron microscopy (SEM) analysis of MgHA/Col scaffolds seeded with MC3T3-E1 cells and SA bacteria. MC3T3-E1 cells were seeded on MgHA/Col 3D scaffolds and cultured for 6 days. Live SA was then inoculated (MOI of 160:1) and cocultured with MC3T3-E1 cells for $72 \mathrm{~h}$. SEM images (representative of 3 independent experiments) are reported that show: (A) the peculiar microarchitecture of an empty MgHA/Col scaffold (scale bar: $20 \mu \mathrm{m})$; (B,C) a scaffold colonized by SA (scale bars: $20 \mu \mathrm{m}$ and $5 \mu \mathrm{m}$, respectively); (D) a scaffold seeded with MC3T3-E1 cells only (scale bar: $20 \mu \mathrm{m}) ;(\mathbf{E}, \mathbf{F})$ SA infection of an MC3T3-E1-seeded scaffold at 24 (E) and 72 (F) hours post infection (scale bars: $20 \mu \mathrm{m}$ and $10 \mu \mathrm{m}$, respectively). In D, E, and F the blue arrowheads indicate MC3T3-E1 cells.

Furthermore, we quantitated activity and/or concentration of osteogenic and inflammatory soluble markers in the conditioned medium of SA/MC3T3-E1 cocultures on $\mathrm{MgHA} / \mathrm{Col}$ scaffolds at 24, 48, and $72 \mathrm{~h}$ from bacterial inoculation. Specifically, we determined ALP enzymatic activity (a specific index of the osteogenic activity of MC3T3-E1 cells) and found it to decrease during infection (Figure 6C), consistent with the trend observed at the mRNA level (Figure 6B). Concentration of OPG (a well-characterized inhibitor of osteoclastogenesis and bone resorption) did not change at the observation times (Figure 6C). Similarly, the PTX3 protein was secreted and dosed in the conditioned medium and had an incremental yet not significant trend in the course of the infection (Figure 6C), thus reflecting the gene transcription profile reported in Figure $6 \mathrm{~B}$. No changes over time were observed in the concentration/activity of ALP, OPG, PTX3, and TNF- $\alpha$ (which was undetectable in the 3D setting) in the supernatant of 2D cultures (Figure 6C). Furthermore, ALP activity was higher in $3 \mathrm{D}$ than $2 \mathrm{D}$ conditioned media at $24 \mathrm{~h}$, which was reversed at $72 \mathrm{~h}$, while the concentration of OPG was consistently more elevated in 3D than 2D conditioned media at all time points, and PTX3 was significantly more abundant in 2D than $3 \mathrm{D}$ cocultures at $72 \mathrm{~h}$ only. These data collectively suggest MgHA/Col-dependent effects on the ability of SA-infected MC3T3-E1 cells to synthesize and release both osteogenic (ALP and OPG) and inflammatory (TNF- $\alpha$ and PTX3) mediators. 

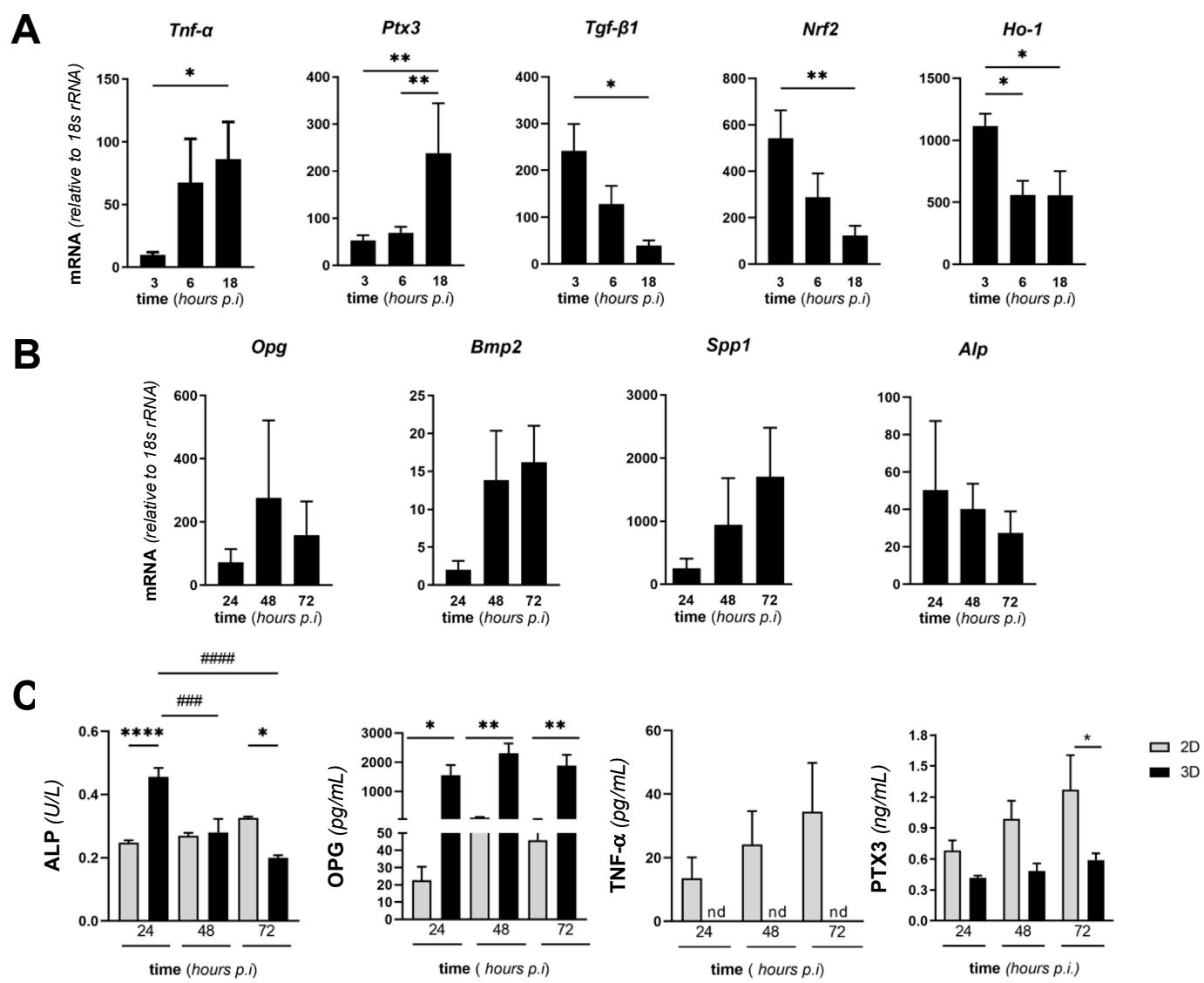

Figure 6. Expression of selected genes and proteins in MgHA/Col-seeded MC3T3-E1 cells infected with SA. MC3T3-E1 cells were seeded on MgHA/Col 3D scaffolds and cultured for 6 days. Live SA was then inoculated (MOI of 160:1) and cocultured with MC3T3-E1 cells up to $72 \mathrm{~h}$. (A,B) Cells were harvested the reported time points, total RNA was extracted, and mRNA levels of the indicated genes were measured by qRT-PCR. Data were normalized based on the levels of $18 \mathrm{~S}$ rRNA, and expressed as mean \pm SEM ( $n=4-6$ from 2 to 3 independent experiments performed in duplicate). (C) Activity of ALP and concentration of OPG and PTX3 in the conditioned medium of MC3T3-E1/SA cocultures were determined using commercial enzymatic and ELISA kits. Data are from 3 to 4 independent experiments performed in duplicate or triplicate $\left(n=6-8\right.$, mean \pm SEM). In panels A and $\mathrm{B},{ }^{* *} p<0.01$ and ${ }^{*} p<0.05$, one-way ANOVA test with Dunn's multiple comparisons test. In panel $\mathrm{C},{ }^{* * * *} p<0.0001,{ }^{* * *} p<0.001,{ }^{* *} p<0.01$, and ${ }^{*} p<0.05$ (comparison of the observations recorded from 3D and 2D settings at the same time points), and \#\#\# $p<0.0001$, \#\#\# $p<0.001$, \#\# $p<0.01$, and \# $p<0.05$ (comparison of the observations recorded at different time points from the same setting, i.e., either 2D or 3D) two-way ANOVA with Sidak's multiple comparisons test.

\subsection{Expression of Virulence SA Genes in MC3T3-E1/SA Cocultures}

We then evaluated the expression of SA genes coding for key virulence factors both in 2D and in 3D MC3T3-E1/SA cocultures. Specifically, we investigated Staphylococcus protein A (SpA, a major survival and virulence factor of $\mathrm{SA}$ ), phenol soluble modulin $\mathrm{A}$ ( $p s m A$, a bacterial toxin with cytolytic activity), accessory gene regulator ( $a g r$, an essential component of the SA quorum-sensing system), clumping factor A (ClfA), and fibronectin binding protein $(F n b p)$, which are both involved in bacteria clumping and fibronectin binding $[26,41,46,47]$. Our data indicate increased transcription of all these genes during infection of the MC3T3-E1 cells, except for agr and Fnbp whose mRNA levels were unchanged (Figure 7). Of note, all these genes had higher expression in the 3D setting than in 2D cultures (Figure 7) and their transcription did not change in the course of the infection in the 2D model (as opposed to 3D). 

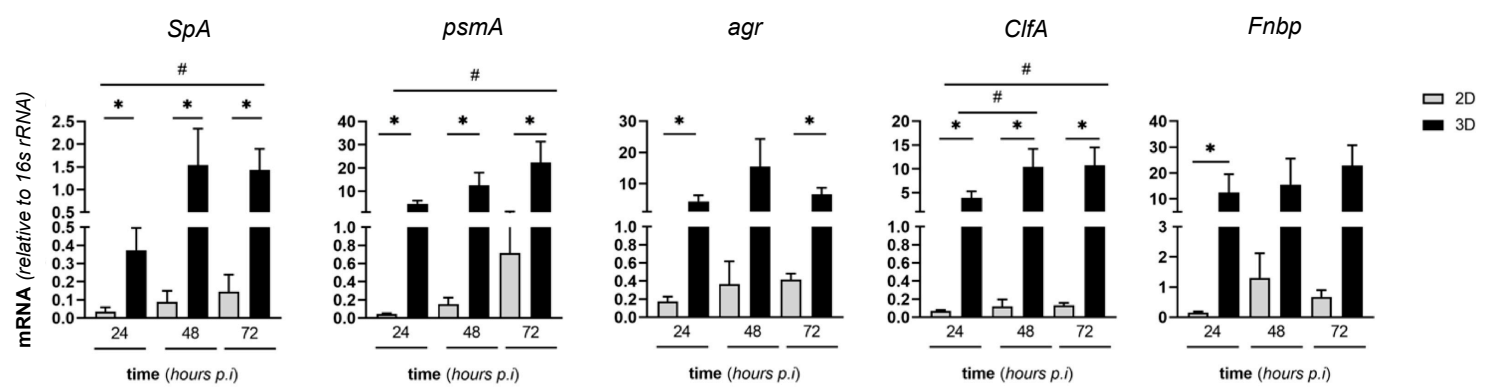

Figure 7. Expression of virulence SA genes in MC3T3-E1/SA cocultures. MC3T3-E1 cells were seeded on MgHA/Col 3D scaffolds, cultured, and challenged with SA as described in Figure 6. Cells were harvested at the reported time points, total RNA was extracted, and mRNA levels of the indicated bacterial genes were measured by qRT-PCR. Data were normalized based on the levels of 16S rRNA, and expressed as mean \pm SEM (two independent experiments performed in triplicate or quadruplicate, $n=7$ ). ${ }^{* *} p<0.01$ and ${ }^{*} p<0.05$, one-way ANOVA test with Dunn's multiple comparisons test (comparison of the observations recorded at different time points from the same setting, i.e., either 2D or 3D). \# $p<0.05$, Mann-Whitney test (comparison of the observations recorded from 3D and 2D settings at the same time points).

\section{Discussions}

Staphylococcus aureus is amongst the most common human pathogens and a primary etiologic agent of bone infections, with major regard to OM [27], whereby it is responsible for alterations and loss of the bone cells homeostasis [13]. The pathogenetic mechanisms of this debilitating disease are not fully elucidated and deserve urgent investigations. Traditional in vitro models to study the host-pathogen interphase in OM are based on 2D monolayers of cells. These experimental settings are far from reproducing the structural complexity of the bone microenvironment, which poses severe limitations on the relevance of such modeling strategies to the human pathology [6]. Three-dimensional models of OM have been reported that mimic some characteristics of the BEM. Kavanagh et al. developed a 3D model of bone infection to examine colonization and infection of MC3T3 cells by SA on EDAC (1-ethyl-3-(3-dimethylaminopropyl)carbodiimide) cross-linked glycosaminoglycan collagen scaffolds [6]. In this setting, SA-infected MC3T3-E1 cells had increased bone matrix-deposition activity, a phenomenon that mimics the human pathology where OBs counteract infection-induced bone loss by increasing bone mineralization [6]. To study in vitro postoperative SA biofilm-dependent osteomyelitis, Raic et al. implemented a 3D model based on human hematopoietic stem and progenitor cells (HSPCs) and mesenchymal stromal cells (MSCs) cultured on cationized bovine serum albumin (cBSA) scaffolds, which simulates implant-associated osteomyelitis [48]. Additional strategies have been exploited to model OM in vitro using 3D systems (reviewed in [3,49]), which allowed studying specific pathogenetic mechanisms of the disease, including intracellular colonization of non-professional phagocytes (like OBs, OCs, and osteocytes), a process that is believed to contribute to bacterial persistence, chronic infection, and antibiotic resistance [50-52]. However, currently available 3D models of OM share a common limitation, i.e., poor reproduction of the natural BEM, which is an essential player in SA adhesion, biofilm formation, and infection of bone cells [12].

To overcome this limitation, here we propose a composite system in which 3D biomimetic scaffolds made of $\mathrm{MgHA} / \mathrm{Col}$ mixed matrix are seeded with the murine MC3T3-E1 osteoblast precursor cell line and infected with SA. The MgHA/Col scaffolds have already demonstrated high biocompatibility with different osteogenic cells, such as murine and human mesenchymal stem cells and human osteosarcoma cell lines (MG63 and SAOS-2) $[37-39,53,54]$, while to the best of our knowledge the osteoblast cell line MC3T3-E1 derived from primary mouse calvaria has been used here for the first time. In line with previous work on other osteogenic cells, we found that MC3T3-E1 cells adapted to the 3D culture on $\mathrm{MgHA} / \mathrm{Col}$ scaffolds, proliferated, were metabolically active, and shaped their gene expression according to a more advanced differentiation state by increasing, for instance, the mRNA levels of Bmp2 and Spp1 genes, as compared to 2D conditions 
(Figure 1). Notably, 3D culturing did not activate inflammatory and antioxidant responses, which are expected to inhibit the osteogenic functions of OBs [44,45].

SA-induced orthopedic infections constitute a major health threat; therefore, much effort has been devoted to unravel the underlying pathogenetic mechanisms. A variety of experimental settings have been implemented to mimic the host-pathogen interaction, comprising collagen glycosaminoglycan scaffolds, titanium substrates coated with $\mathrm{MgHA}$ or silicon and copper, or polylactic acid nanofibers coated with a silver-releasing polymer $[6,55,56]$. Nevertheless, also in this respect the use of MgHA/Col scaffolds, displaying the key features of the bone matrix, is a novelty and an important advancement. In fact, although valuable for specific research purposes (e.g., biofilm formation and infection of OB by SA), those systems lack either the mineral or the organic component or the spatial cues encountered by SA in the natural bone. In our MgHA/Col scaffolds, all these features are present and ideally organized due to a bioinspired manufacturing process. By using different techniques, we showed that these scaffolds per se support both survival and colonization of SA (Figures 2 and 5), which allowed the subsequent development of MC3T3-E1/SA 3D cocultures (Figures 4 and 5) and comparison with parallel 2D experiments (Figure 3). This highlighted important differences between the 2D and 3D settings. First, the MC3T3-E1 cells were more sensitive to SA infection when cultured in 2D conditions, as demonstrated by a strong reduction in cell survival, in accordance with previous studies [20-24], and an increase in metabolic activity (Figure 3). Second, we focused on the early phases of the SA infection (that are relevant to bacterial adhesion and biofilm formation [3,41]), and observed different kinetics (between 2D and 3D) for the expression of inflammatory and antioxidant genes (Figure 6), with major regard to the long pentraxin PTX3, a well-established PRM with emerging roles in bone physiology and pathology $[18,42]$. Regarding the bacterial counterpart in our coculture models, lower bacterial loads were found in the $3 \mathrm{D}$ compared to the $2 \mathrm{D}$ setting at all time points (Figure 3). Additionally, and more interestingly, SA genes coding for key virulence factor (SpA, PSM-A, agr, ClfA, and FnBP) had much more increased expression in the 3D than in the 2D setting (Figure 7). Possible explanations for these divergent responses could be a different engagement of MC3T3-E1 and SA in cell-cell and cell-matrix interactions in the two models, or a diverse cell-bacteria interplay affecting viability, gene expression, and virulence. Interestingly, a recent paper demonstrated that magnesium-based composite scaffolds had a bacterial inhibition potential proportional to their magnesium content. In fact, sustained ion release over time owing to scaffold dissolution caused alkalinization of the supernatant, generating a poorly permissive milieu for the bacteria [33]. We may hypothesize that a similar situation occurred in our 3D model, particularly in the presence of MC3T3-E1, which may have contributed to scaffold remodeling along the culture.

Previous studies demonstrated that OB infection by SA induces inflammatory cytokine release and alters the osteogenic functions of these cells [8-11]. These findings were recapitulated in our 3D experimental setting, thus supporting the validity of this model as a new tool to model and investigate the SA-OM. In this regard, the bone biominetic microenvironment of the $\mathrm{MgHA} / \mathrm{Col}$ scaffolds here described appears closer to the in vivo situation than conventional 2D settings and other 3D models described in the literature and deserves further investigation by means of omics approaches targeted both to the osteoblastic cell and to the bacterial component.

We recognize that our work had some limitations. Specifically, a single bacterial strain was used in our coculture experiments. However, in a recent work, Musso and colleagues [40] infected the human MG63 osteoblast-like cell line with four methicillinresistant and one methicillin-sensitive SA clones in a classical 2D setting and found that these bacterial strains elicited different effects in terms of biochemical cell functions related to inflammation, cell metabolism, and oxidative stress. On the same line, we cannot exclude that in our setting too the use of a different SA strain might have produced different results to the ones here reported. Therefore, as a perspective it will be interesting to challenge our 3D model with other bacterial strains (even beyond the Staphylococcus genus), which will 
also allow testing specific mechanistic hypothesis. Moreover, our 3D model represents a simplified pathological scenario owing to the presence of a single skeletal cell type. While a model with reduced complexity is useful for basic understanding of biological processes, we may envisage further implementations of our model through addition of other cell types present in the bone tissue, in order to gain a broader overview of the OM pathogenesis.

\section{Materials and Methods}

\subsection{Staphylococcus aureus Strain and Growth}

The Staphylococcus aureus strain used in this study was an antibiotic-sensitive Newman clinical isolate [57]. SA was expanded by incubation in tryptic soy broth (TSB, Waltham, $\mathrm{MA}, \mathrm{USA}$ ) at $37^{\circ} \mathrm{C}$ and $200 \mathrm{rpm}$, and harvested on the day of the infection experiments (see below) when an optical density at $600 \mathrm{~nm}$ of 0.6 was achieved (i.e., start of the exponential growth phase), corresponding to $1 \times 10^{8} \mathrm{CFU}$ (colony-forming unit)/mL. Optical densities were measured using a GeneQuant pro spectrophotometer (Amersham Biosciences, Little Chalfont, UK) and CFUs counted as detailed below. Prior to infection, bacteria were resuspended with the alpha minimum essential medium containing ribonucleosides, deoxyribonucleosides, $2 \mathrm{mM}$ L-glutamine, and $1 \mathrm{mM}$ sodium pyruvate ( $\alpha$-MEM, Waltham, MA, USA), supplemented with $10 \%$ FBS in the absence of penicillin/streptomycin (P/S) and ascorbic acid. In some experiments, SA was inactivated by overnight incubation with $2 \%(w / v)$ paraformaldehyde, followed by quenching with $50 \mathrm{mM} \mathrm{NH}_{4} \mathrm{Cl}$, then washed, and resuspended with phosphate buffered saline (PBS).

\subsection{The 2D Cultures of MC3T3-E1 Cells on Plastic Plates}

The murine osteoblastic MC3T3-E1 cell line (Subclone 14) used throughout the study was a gift by Professor Fernando Gianfrancesco (CNR-IGB, Naples). Cells were expanded by incubation at $37^{\circ} \mathrm{C}$ and $5 \% \mathrm{CO}_{2}$ with $\alpha$-MEM supplemented with $10 \%$ FBS and $2 \%$ penicillin/streptomycin (the culture medium was changed twice a week). For 2D cultures on plastic plates, MC3T3-E1 cells were harvested using trypsin EDTA (Sigma-Aldrich, St. Louis, MO, USA), and seeded onto uncoated 48 well cell culture plates (Corning, New York, NY, USA) at $3 \times 10^{5}$ cells / well using the same medium without $\mathrm{P} / \mathrm{S}$.

\subsection{The 3D Cultures of MC3T3-E1 Cells on Magnesium-Doped Hydroxyapatite/Collagen I (MgHA/Col) Scaffolds}

$\mathrm{MgHA} / \mathrm{Col}$ scaffolds were produced as previously described [37-39]. These were conditioned in 48 well cell culture plates with $\alpha$-MEM without $\mathrm{P} / \mathrm{S}$ for $2 \mathrm{~h}$ at $37^{\circ} \mathrm{C}$ prior to seeding of the MC3T3-E1 cells. Conditioned scaffolds were transferred into new wells and the top surface of each was seeded with $20 \mu \mathrm{L}$ of half the cell suspension $\left(5 \times 10^{5}\right.$ cells $)$. Plates were incubated for $15 \mathrm{~min}$ to allow cell attachment and scaffolds were turned over to seed the remaining cell suspension $\left(20 \mu \mathrm{L}\right.$ containing $5 \times 10^{5}$ cells $)$ onto the opposite surface. Following a second incubation of $15 \mathrm{~min}, \alpha$-MEM without $\mathrm{P} / \mathrm{S}$ was added to each well $(700 \mu \mathrm{L} /$ well $)$ and plates were moved to the incubator. Proliferation and metabolic activity of osteoblasts were measured every 3 days up to 9 days of culturing to monitor adaptation of these cells to the MgHA/Col scaffolds. See Figure S1 in Supplementary Materials for a scheme of the experimental design.

\subsection{Infection Experiments (SA/MC3T3-E1 2D and 3D Cocultures)}

MC3T3-E1 cells, either grown on 48 well cell culture plates (2D) or on MgHA/Col scaffolds (3D), were infected with live SA at MOI (multiplicity of infection) of 160:1 (160 × 10 bacteria: $1 \times 10^{6}$ MC3T3-E1 cells). Expression of selected genes by MC3T3-E1 and SA, bacterial CFUs, concentration of ALP, OPG, TNF- $\alpha$, and PTX3 in the conditioned medium and viability of the MC3T3-E1 cells were assessed at different time points up to 3 days of culturing in both 2D and 3D conditions, as detailed below. In some experiments, the metabolic activity of MC3T3-E1 cells was determined using inactivated SA. 


\subsection{Assay for Proliferation of MC3T3-E1 Cells}

Proliferation of the MC3T3-E1 cells was assessed by quantifying genomic DNA using the PicoGreen assay (Invitrogen). MC3T3-E1 cells grown either on plastic plates or on $\mathrm{MgHA} / \mathrm{Col}$ scaffolds were lysed using $10 \mathrm{mM}$ Tris-HCl and $1 \mathrm{mM}$ EDTA (TE) buffer containing $0.2 \%(w / v)$ Triton X-100, followed by three freeze-and-thaw cycles. Lysed samples were incubated with the PicoGreen reagent according to the manufacturer's instructions, and fluorescence intensity was measured at $538 \mathrm{~nm}$ following excitation at $485 \mathrm{~nm}$ using a ClarioStar plate reader (BMG Labtech, Ortenberg, Germany). The contribution of bacterial DNA (DNA $\mathrm{DA}_{\mathrm{SA}}$ ) to the PicoGreen signals recorded from SA/MC3T3-

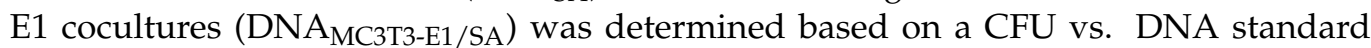

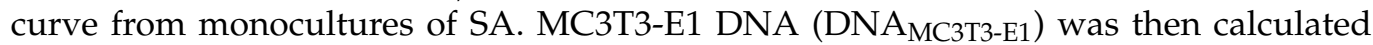
by subtracting $\mathrm{DNA}_{\mathrm{SA}}$ from $\mathrm{DNA}_{\mathrm{MC} 3 \mathrm{~T} 3-\mathrm{E} 1 / \mathrm{SA}}$ (i.e., $\mathrm{DNA}_{\mathrm{MC} 3 \mathrm{~T} 3-\mathrm{E} 1}=\mathrm{DNA}_{\mathrm{MC} 3 \mathrm{~T} 3-\mathrm{E} 1 / \mathrm{SA}}-$ DNA $\left._{S A}\right)$.

\subsection{Assay for Metabolic Activity of MC3T3-E1 Cells}

The Alamar Blue assay (Thermo Fisher Scientific, Waltham, MA, USA) was used to measure the metabolic activity of MC3T3-E1 cells cultured in 2D or 3D conditions in the presence and absence of inactivated SA. Following addition of the Alamar Blue reagent, plates were incubated for $4 \mathrm{~h}$ at $37^{\circ} \mathrm{C}$ and $70 \mathrm{rpm}$ with $5 \% \mathrm{CO}_{2}$. After incubation, $100 \mu \mathrm{L}$ of conditioned medium were transferred to black 96 well plates (Corning) and fluorescence intensity was recorded at $560 \mathrm{~nm}$ following excitation at $590 \mathrm{~nm}$ using a ClarioStar plate reader.

\subsection{CFU Counting}

SA CFUs were measured both from 2D and 3D MC3T3-E1/SA cocultures. Briefly, MC3T3-E1 cells were washed three times with PBS to remove loosely adherent bacteria, then $1 \mathrm{~mL} /$ well of TSB was added. MC3T3-E1 cells were ruptured either by scraping (2D) or ultrasonication (3D) for $20 \mathrm{~min}$ at $150 \mathrm{~W}$ and $50 \mathrm{~Hz}$ in an ultrasonic bath (Ultrasonic cleaning instrument, Falc Instruments, Treviglio, Italy). Supernatants were collected, diluted 1 in 10, plated on tryptic soy agar (TSA) plates (Becton Dickinson, Milan, Italy), and incubated at $37^{\circ} \mathrm{C}$ for $24 \mathrm{~h}$.

\subsection{Fluorescence Microscopy}

$\mathrm{MgHA} / \mathrm{Col}$ scaffolds (i.e., from 3D monocultures of either SA or MC3T3-E1 cells or 3D SA/MC3T3-E1 cocultures) were transferred to histology cassettes and kept in $4 \%$ neutralbuffered formalin for $24 \mathrm{~h}$. Then they were dehydrated using increasing concentrations of alcohol (70-100\% ethanol), cleared with xylene, and embedded in paraffin. The paraffin section of the scaffolds $(3 \mu \mathrm{m})$ were deparaffinized with xylene and rehydrated using decreasing concentrations of alcohol (100-70\% ethanol) and water, then washed with PBS. The samples then saturated with PBS containing 2\% (w/v) BSA for $45 \mathrm{~min}$, and incubated with a FITC-conjugated anti-Staphylococcus aureus antibody (Abcam, Cambridge, UK). Nuclei were stained by incubation with $30 \mu \mathrm{g} / \mathrm{mL}$ of propidium iodide (PI) for $5 \mathrm{~min}$ at room temperature (RT). Sections were then mounted onto a glass slide using Dabco mounting media, and scanned for fluorescence using a DMI8 inverted fluorescent microscope (Leica, Wetzlar, Germany).

\subsection{Scanning Electron Microscopy (SEM)}

Empty scaffolds and scaffolds coming from the monoculture and coculture experiments were harvested at different time points and washed with cold 0.1 M sodium cacodylate buffer, $\mathrm{pH} 7.4$ (washing buffer). Then they were fixed with glutaraldehyde $2.5 \%$ dissolved in washing buffer and incubated for $2 \mathrm{~h}$ at $4{ }^{\circ} \mathrm{C}$. After fixation, scaffolds were rinsed with washing buffer. The samples were dehydrated with passages in a series of increasing scale alcohol, followed by two final passages with hexamethyldisilazane (Sigma- 
Aldrich) at RT. Dehydrated samples were sputter-coated with gold ( $20 \mu \mathrm{m}$ gold film) and observed by using Stereoscan 360 SEM (Cambridge Instruments, Cambridge, UK).

\subsection{RNA Extraction}

Cell-seeded MgHA/Col scaffolds were washed with PBS and placed in $350 \mu \mathrm{L}$ of digestion buffer $(0.025 \%$ trypsin, $1 \mathrm{mg} / \mathrm{mL}$ collagenase IV in HBSS) for $5 \mathrm{~min}$, with gentle pipetting every $2 \mathrm{~min}$. Reaction mixtures were transferred to clean wells, blocked with $350 \mu \mathrm{L}$ of FBS $+2 \mu \mathrm{L}$ of $1 \mathrm{M}$ EDTA, and centrifuged for $5 \mathrm{~min}$ at $1200 \mathrm{rpm}$ and RT. The resulting pellets were resuspended with $600 \mu \mathrm{L} /$ each of Trizol (Thermo Fisher Scientific), and total RNA isolation was performed according to standard procedures. In 2D experiments, MC3T3-E1 cells were directly incubated with $250 \mu \mathrm{L} /$ well of Trizol prior to RNA extraction.

\subsection{Gene Expression Analysis}

Reverse transcription was carried out using $1 \mu \mathrm{g}$ of total RNA and the High Capacity cDNA Reverse Transcription Kit (Applied Biosystems, Foster City, CA, USA). Quantitative RT-PCR was performed using SsoAdvanced ${ }^{\mathrm{TM}}$ SYBR $^{\circledR}$ Green Supermix (Bio-Rad, Hercules, CA, USA). See Supplementary Materials for sequences of the primers used for murine (Supplementary Table S1) and bacterial (Supplementary Table S2) genes.

\subsection{Enzyme-Linked Immunosorbent Assays (ELISA) and ALP Enzymatic Activity}

The conditioned medium of both 2D and 3D SA/MC3T3-E1 cocultures was centrifuged for $5 \mathrm{~min}$ at $13,000 \mathrm{rpm}$ and $4{ }^{\circ} \mathrm{C}$, to remove bacteria, and the concentration of TNF- $\alpha$, OPG, and PTX3 was determined using commercial ELISA kits (R\&D Systems, Minneapolis, MN, USA), according to the manufacturer's instructions. ALP enzymatic activity was quantified using the Alkaline Phosphatase Activity Colorimetric Assay kit (BioVision, Milpitas, CA, USA).

\subsection{Statistical Analysis}

Statistical analysis and graphical representation of data were carried out using GraphPad Prism version 7.0 (GraphPad Software, Inc., San Diego, CA, USA). Data are represented as mean \pm standard error (SEM). Within-group comparisons were performed by one-way analysis (ANOVA) followed by Dunn's or Sidak multiple comparisons post hoc test. Between-group comparisons were carried out using the Mann-Whitney test. Results were regarded as significantly different if the test's two-tailed p-value was below 0.05 .

\section{Conclusions}

The work presented here demonstrates that $\mathrm{MgHA} / \mathrm{Col}$ matrices closely mimic the physiological environment of the natural human bone and provide a suitable scaffold for 3D models of OM. Due to their cytocompatibility and cell adhesive properties, these biomimetic scaffolds are particularly amenable to study early events in OM pathogenesis, with major regard to bacterial adhesion and OB infection. Additionally, the applied $\mathrm{MgHA} / \mathrm{Col}$ matrices are intrinsically bioactive, in that they are endowed with chemical and mechanical cues that shape and inform both $\mathrm{OB}$ and SA biological responses. Therefore, the 3D model here developed is a close-to-in vivo representation of the host-pathogen interface in OM and stands as a novel and useful tool to study human bone infections in a relevant setting to the human pathology.

\section{Patents}

The authors declare no patents related to the objects of the study.

Supplementary Materials: The following are available online at https://www.mdpi.com/article/10 .3390 / pathogens10070837/s1, Table S1: RT-PCR murine primers. Table S2: RT-PCR Staphylococcus aureus primers. Figure S1: Experimental design and outcomes of the in vitro model of OM developed 
in the study (MC3T3-E1/SA cocultures on MgHA/Col bone biomimetic scaffolds). Figure S2: Gene expression of SA-infected MC3T3-E1 cells in 2D cocultures.

Author Contributions: Conceptualization, R.P., C.S. and A.I.; Data curation, R.P., V.P. and M.L.S.; Formal analysis, R.P., V.P. and M.L.S.; Funding acquisition, A.M. and A.I.; Investigation, R.P., V.P., M.L.S. and E.C.; Methodology, R.P., C.M., C.S. and A.I.; Project administration, C.S. and A.I.; Resources, E.C., M.S., A.T., C.S. and A.I.; Supervision, C.S. and A.I.; Validation, M.L.S.; Visualization, R.P., V.P., M.L.S. and E.C.; Writing-original draft, R.P. and V.P.; Writing-review and editing, C.M., M.L., A.D., B.B., A.M., M.S., A.T., C.S. and A.I. All authors have read and agreed to the published version of the manuscript.

Funding: This research was funded by Fondazione Beppe e Nuccy Angiolini.

Institutional Review Board Statement: Not applicable.

Informed Consent Statement: Not applicable.

Data Availability Statement: Data supporting the reported results can be found at https://zenodo. org/communities / humanitasirccs (accessed on 1 June 2021). and will be made available upon request to the corresponding authors.

Acknowledgments: We would like to thank Fernando Gianfrancesco (CNR-IGB, Naples) for the kind gift of MC3T3 cell line.

Conflicts of Interest: The authors declare no conflict of interest. The funders had no role in the design of the study; in the collection, analyses, or interpretation of data; in the writing of the manuscript, or in the decision to publish the results.

\section{References}

1. Nasser, A.; Azimi, T.; Ostadmohammadi, S. A comprehensive review of bacterial osteomyelitis with emphasis on Staphylococcus aureus. Microb. Pathog. 2020, 148, 104431. [CrossRef]

2. McNeil, J.C. Acute Hematogenous Osteomyelitis in Children: Clinical Presentation and Management. Infect. Drug Resist. 2020, 13, 4459-4473. [CrossRef]

3. Hofstee, M.I.; Muthukrishnan, G.; Atkins, G.J.; Riool, M.; Thompson, K.; Morgenstern, M.; Stoddart, M.J.; Richards, R.G.; Zaat, S.A.J.; Moriarty, T.F. Current Concepts of Osteomyelitis: From Pathologic Mechanisms to Advanced Research Methods. Am. J. Pathol. 2020, 190, 1151-1163. [CrossRef] [PubMed]

4. Lew, D.P.; Waldvogel, F.A. Osteomyelitis. Lancet 2004, 364, 369-379. [CrossRef]

5. Spellberg, B.; Lipsky, B.A. Systemic antibiotic therapy for chronic osteomyelitis in adults. Clin. Infect. Dis. $2012,54,393-407$. [CrossRef]

6. Kavanagh, N.; Ryan, E.J.; Widaa, A.; Sexton, G.; Fennell, J.; O’Rourke, S.; Cahill, K.C.; Kearney, C.J.; O’Brien, F.J.; Kerrigan, S.W. Staphylococcal Osteomyelitis: Disease Progression, Treatment Challenges, and Future Directions. Clin. Microbiol. Rev. 2018, 31. [CrossRef] [PubMed]

7. Walter, G.; Kemmerer, M.; Kappler, C.; Hoffmann, R. Treatment algorithms for chronic osteomyelitis. Dtsch. Arztebl. Int. 2012, 109, 257-264. [CrossRef] [PubMed]

8. Muthukrishnan, G.; Masters, E.A.; Daiss, J.L.; Schwarz, E.M. Mechanisms of Immune Evasion and Bone Tissue Colonization That Make Staphylococcus aureus the Primary Pathogen in Osteomyelitis. Curr. Osteoporos. Rep. 2019, 17, 395-404. [CrossRef]

9. Libraty, D.H.; Patkar, C.; Torres, B. Staphylococcus aureus reactivation osteomyelitis after 75 years. N. Engl. J. Med. 2012, 366, 481-482. [CrossRef] [PubMed]

10. Cheng, A.G.; DeDent, A.C.; Schneewind, O.; Missiakas, D. A play in four acts: Staphylococcus aureus abscess formation. Trends Microbiol. 2011, 19, 225-232. [CrossRef]

11. De Mesy Bentley, K.L.; Trombetta, R.; Nishitani, K.; Bello-Irizarry, S.N.; Ninomiya, M.; Zhang, L.; Chung, H.L.; McGrath, J.L.; Daiss, J.L.; Awad, H.A.; et al. Evidence of Staphylococcus Aureus Deformation, Proliferation, and Migration in Canaliculi of Live Cortical Bone in Murine Models of Osteomyelitis. J. Bone Miner. Res. 2017, 32, 985-990. [CrossRef]

12. Foster, T.J.; Geoghegan, J.A.; Ganesh, V.K.; Hook, M. Adhesion, invasion and evasion: The many functions of the surface proteins of Staphylococcus aureus. Nat. Rev. Microbiol. 2014, 12, 49-62. [CrossRef]

13. Josse, J.; Velard, F.; Gangloff, S.C. Staphylococcus aureus vs. Osteoblast: Relationship and Consequences in Osteomyelitis. Front. Cell Infect. Microbiol. 2015, 5, 85. [CrossRef]

14. Claro, T.; Widaa, A.; O'Seaghdha, M.; Miajlovic, H.; Foster, T.J.; O’Brien, F.J.; Kerrigan, S.W. Staphylococcus aureus protein A binds to osteoblasts and triggers signals that weaken bone in osteomyelitis. PLoS ONE 2011, 6, e18748. [CrossRef] [PubMed]

15. Thammavongsa, V.; Kim, H.K.; Missiakas, D.; Schneewind, O. Staphylococcal manipulation of host immune responses. Nat. Rev. Microbiol. 2015, 13, 529-543. [CrossRef] [PubMed] 
16. Brandt, S.L.; Putnam, N.E.; Cassat, J.E.; Serezani, C.H. Innate Immunity to Staphylococcus aureus: Evolving Paradigms in Soft Tissue and Invasive Infections. J. Immunol. 2018, 200, 3871-3880. [CrossRef] [PubMed]

17. Parente, R.; Doni, A.; Bottazzi, B.; Garlanda, C.; Inforzato, A. The complement system in Aspergillus fumigatus infections and its crosstalk with pentraxins. FEBS Lett. 2020, 594, 2480-2501. [CrossRef]

18. Parente, R.; Sobacchi, C.; Bottazzi, B.; Mantovani, A.; Grcevic, D.; Inforzato, A. The Long Pentraxin PTX3 in Bone Homeostasis and Pathology. Front. Immunol. 2019, 10, 2628. [CrossRef]

19. Kathariya, R.; Jain, H.; Gujar, D.; Singh, A.; Ajwani, H.; Mandhyan, D. Pentraxins as key disease markers for periodontal diagnosis. Dis. Markers 2013, 34, 143-151. [CrossRef] [PubMed]

20. Jin, T.; Zhu, Y.L.; Li, J.; Shi, J.; He, X.Q.; Ding, J.; Xu, Y.Q. Staphylococcal protein A, Panton-Valentine leukocidin and coagulase aggravate the bone loss and bone destruction in osteomyelitis. Cell. Physiol. Biochem. 2013, 32, 322-333. [CrossRef]

21. Alexander, E.H.; Rivera, F.A.; Marriott, I.; Anguita, J.; Bost, K.L.; Hudson, M.C. Staphylococcus aureus-Induced tumor necrosis factor-Related apoptosis-Inducing ligand expression mediates apoptosis and caspase- 8 activation in infected osteoblasts. BMC Microbiol. 2003, 3, 5. [CrossRef]

22. Cassat, J.E.; Hammer, N.D.; Campbell, J.P.; Benson, M.A.; Perrien, D.S.; Mrak, L.N.; Smeltzer, M.S.; Torres, V.J.; Skaar, E.P. A secreted bacterial protease tailors the Staphylococcus aureus virulence repertoire to modulate bone remodeling during osteomyelitis. Cell Host Microbe 2013, 13, 759-772. [CrossRef]

23. Rasigade, J.P.; Trouillet-Assant, S.; Ferry, T.; Diep, B.A.; Sapin, A.; Lhoste, Y.; Ranfaing, J.; Badiou, C.; Benito, Y.; Bes, M.; et al. PSMs of hypervirulent Staphylococcus aureus act as intracellular toxins that kill infected osteoblasts. PLoS ONE 2013, 8, e63176. [CrossRef] [PubMed]

24. Deplanche, M.; Mouhali, N.; Nguyen, M.T.; Cauty, C.; Ezan, F.; Diot, A.; Raulin, L.; Dutertre, S.; Langouet, S.; Legembre, P.; et al. Staphylococcus aureus induces DNA damage in host cell. Sci. Rep. 2019, 9, 7694. [CrossRef] [PubMed]

25. Somayaji, S.N.; Ritchie, S.; Sahraei, M.; Marriott, I.; Hudson, M.C. Staphylococcus aureus induces expression of receptor activator of NF-kappaB ligand and prostaglandin E2 in infected murine osteoblasts. Infect. Immun. 2008, 76, 5120-5126. [CrossRef] [PubMed]

26. Widaa, A.; Claro, T.; Foster, T.J.; O’Brien, F.J.; Kerrigan, S.W. Staphylococcus aureus protein A plays a critical role in mediating bone destruction and bone loss in osteomyelitis. PLoS ONE 2012, 7, e40586. [CrossRef] [PubMed]

27. Wright, J.A.; Nair, S.P. Interaction of staphylococci with bone. Int. J. Med. Microbiol. 2010, 300, 193-204. [CrossRef] [PubMed]

28. Reizner, W.; Hunter, J.G.; O'Malley, N.T.; Southgate, R.D.; Schwarz, E.M.; Kates, S.L. A systematic review of animal models for Staphylococcus aureus osteomyelitis. Eur. Cells Mater. 2014, 27, 196-212. [CrossRef]

29. Proctor, R.A.; von Eiff, C.; Kahl, B.C.; Becker, K.; McNamara, P.; Herrmann, M.; Peters, G. Small colony variants: A pathogenic form of bacteria that facilitates persistent and recurrent infections. Nat. Rev. Microbiol. 2006, 4, 295-305. [CrossRef]

30. Sendi, P.; Rohrbach, M.; Graber, P.; Frei, R.; Ochsner, P.E.; Zimmerli, W. Staphylococcus aureus small colony variants in prosthetic joint infection. Clin. Infect. Dis. 2006, 43, 961-967. [CrossRef] [PubMed]

31. Baker, B.M.; Chen, C.S. Deconstructing the third dimension: How 3D culture microenvironments alter cellular cues. J. Cell Sci. 2012, 125, 3015-3024. [CrossRef]

32. Fitzgerald, K.A.; Malhotra, M.; Curtin, C.M.; FJ, O.B.; CM, O.D. Life in 3D is never flat: 3D models to optimise drug delivery. J. Control. Release 2015, 215, 39-54. [CrossRef]

33. Ma, R.; Lai, Y.X.; Li, L.; Tan, H.L.; Wang, J.L.; Li, Y.; Tang, T.T.; Qin, L. Bacterial inhibition potential of 3D rapid-prototyped magnesium-based porous composite scaffolds-An in vitro efficacy study. Sci. Rep. 2015, 5, 13775. [CrossRef]

34. Ono, T.; Hayashi, M.; Sasaki, F.; Nakashima, T. RANKL biology: Bone metabolism, the immune system, and beyond. Inflamm. Regen. 2020, 40, 2. [CrossRef] [PubMed]

35. Halloran, D.; Durbano, H.W.; Nohe, A. Bone Morphogenetic Protein-2 in Development and Bone Homeostasis. J. Dev. Biol. 2020, 8, 19. [CrossRef]

36. Singh, R.; Hui, T.; Matsui, A.; Allahem, Z.; Johnston, C.D.; Ruiz-Torruella, M.; Rittling, S.R. Modulation of infection-mediated migration of neutrophils and CXCR2 trafficking by osteopontin. Immunology 2017, 150, 74-86. [CrossRef] [PubMed]

37. Menale, C.; Campodoni, E.; Palagano, E.; Mantero, S.; Erreni, M.; Inforzato, A.; Fontana, E.; Schena, F.; Van't Hof, R.; Sandri, M.; et al. Mesenchymal Stromal Cell-Seeded Biomimetic Scaffolds as a Factory of Soluble RANKL in Rankl-Deficient Osteopetrosis. Stem Cells Transl. Med. 2019, 8, 22-34. [CrossRef]

38. Schena, F.; Menale, C.; Caci, E.; Diomede, L.; Palagano, E.; Recordati, C.; Sandri, M.; Tampieri, A.; Bortolomai, I.; Capo, V.; et al Murine Rankl ${ }^{-/-}$Mesenchymal Stromal Cells Display an Osteogenic Differentiation Defect Improved by a RANKL-Expressing Lentiviral Vector. Stem Cells 2017, 35, 1365-1377. [CrossRef] [PubMed]

39. Sobacchi, C.; Erreni, M.; Strina, D.; Palagano, E.; Villa, A.; Menale, C. 3D Bone Biomimetic Scaffolds for Basic and Translational Studies with Mesenchymal Stem Cells. Int. J. Mol. Sci. 2018, 19, 3150. [CrossRef]

40. Musso, N.; Caruso, G.; Bongiorno, D.; Grasso, M.; Bivona, D.A.; Campanile, F.; Caraci, F.; Stefani, S. Different Modulatory Effects of Four Methicillin-Resistant Staphylococcus aureus Clones on MG-63 Osteoblast-Like Cells. Biomolecules 2021, 11, 72. [CrossRef]

41. Josse, J.; Valour, F.; Maali, Y.; Diot, A.; Batailler, C.; Ferry, T.; Laurent, F. Interaction Between Staphylococcal Biofilm and Bone: How Does the Presence of Biofilm Promote Prosthesis Loosening? Front. Microbiol. 2019, 10, 1602. [CrossRef]

42. Grcevic, D.; Sironi, M.; Valentino, S.; Deban, L.; Cvija, H.; Inforzato, A.; Kovacic, N.; Katavic, V.; Kelava, T.; Kalajzic, I.; et al. The Long Pentraxin 3 Plays a Role in Bone Turnover and Repair. Front. Immunol. 2018, 9, 417. [CrossRef] 
43. Zhang, J.; Koussih, L.; Shan, L.; Halayko, A.J.; Chen, B.K.; Gounni, A.S. TNF up-regulates Pentraxin3 expression in human airway smooth muscle cells via JNK and ERK1/2 MAPK pathways. Allergy Asthma Clin. Immunol. 2015, 11, 37. [CrossRef] [PubMed]

44. Abdelmagid, S.M.; Barbe, M.F.; Safadi, F.F. Role of inflammation in the aging bones. Life Sci. 2015, 123, 25-34. [CrossRef]

45. Zuo, C.; Zhao, X.; Shi, Y.; Wu, W.; Zhang, N.; Xu, J.; Wang, C.; Hu, G.; Zhang, X. TNF-alpha inhibits SATB2 expression and osteoblast differentiation through NF-kappaB and MAPK pathways. Oncotarget 2018, 9, 4833-4850. [CrossRef]

46. Peschel, A.; Otto, M. Phenol-soluble modulins and staphylococcal infection. Nat. Rev. Microbiol. 2013, 11, 667-673. [CrossRef] [PubMed]

47. Seidl, K.; Stucki, M.; Ruegg, M.; Goerke, C.; Wolz, C.; Harris, L.; Berger-Bachi, B.; Bischoff, M. Staphylococcus aureus CcpA affects virulence determinant production and antibiotic resistance. Antimicrob. Agents Chemother. 2006, 50, 1183-1194. [CrossRef]

48. Raic, A.; Riedel, S.; Kemmling, E.; Bieback, K.; Overhage, J.; Lee-Thedieck, C. Biomimetic 3D in vitro model of biofilm triggered osteomyelitis for investigating hematopoiesis during bone marrow infections. Acta Biomater. 2018, 73, 250-262. [CrossRef]

49. Barrila, J.; Crabbe, A.; Yang, J.; Franco, K.; Nydam, S.D.; Forsyth, R.J.; Davis, R.R.; Gangaraju, S.; Ott, C.M.; Coyne, C.B.; et al. Modeling Host-Pathogen Interactions in the Context of the Microenvironment: Three-Dimensional Cell Culture Comes of Age. Infect. Immun. 2018, 86. [CrossRef]

50. Mohamed, W.; Sommer, U.; Sethi, S.; Domann, E.; Thormann, U.; Schutz, I.; Lips, K.S.; Chakraborty, T.; Schnettler, R.; Alt, V. Intracellular proliferation of $S$. aureus in osteoblasts and effects of rifampicin and gentamicin on $\mathrm{S}$. aureus intracellular proliferation and survival. Eur. Cells Mater. 2014, 28, 258-268. [CrossRef] [PubMed]

51. Klenerman, L. A history of osteomyelitis from the Journal of Bone and Joint Surgery: 1948 TO 2006. J. Bone Jt. Surg. Br. 2007, 89, 667-670. [CrossRef]

52. Yang, D.; Wijenayaka, A.R.; Solomon, L.B.; Pederson, S.M.; Findlay, D.M.; Kidd, S.P.; Atkins, G.J. Novel Insights into Staphylococcus aureus Deep Bone Infections: The Involvement of Osteocytes. mBio 2018, 9. [CrossRef]

53. Minardi, S.; Corradetti, B.; Taraballi, F.; Sandri, M.; Van Eps, J.; Cabrera, F.J.; Weiner, B.K.; Tampieri, A.; Tasciotti, E. Evaluation of the osteoinductive potential of a bio-inspired scaffold mimicking the osteogenic niche for bone augmentation. Biomaterials 2015, 62, 128-137. [CrossRef] [PubMed]

54. Bassi, G.; Panseri, S.; Dozio, S.M.; Sandri, M.; Campodoni, E.; Dapporto, M.; Sprio, S.; Tampieri, A.; Montesi, M. Scaffold-based 3D cellular models mimicking the heterogeneity of osteosarcoma stem cell niche. Sci. Rep. 2020, 10, 22294. [CrossRef]

55. Shen, X.; Hu, W.; Ping, L.; Liu, C.; Yao, L.; Deng, Z.; Wu, G. Antibacterial and Osteogenic Functionalization of Titanium With Silicon/Copper-Doped High-Energy Shot Peening-Assisted Micro-Arc Oxidation Technique. Front. Bioeng. Biotechnol. 2020, 8 , 573464. [CrossRef] [PubMed]

56. Mohiti-Asli, M.; Molina, C.; Diteepeng, T.; Pourdeyhimi, B.; Loboa, E.G. Evaluation of Silver Ion-Releasing Scaffolds in a 3D Coculture System of MRSA and Human Adipose-Derived Stem Cells for Their Potential Use in Treatment or Prevention of Osteomyelitis. Tissue Eng. Part A 2016, 22, 1258-1263. [CrossRef]

57. Baba, T.; Bae, T.; Schneewind, O.; Takeuchi, F.; Hiramatsu, K. Genome sequence of Staphylococcus aureus strain Newman and comparative analysis of staphylococcal genomes: Polymorphism and evolution of two major pathogenicity islands. J. Bacteriol. 2008, 190, 300-310. [CrossRef] [PubMed] 